\title{
Varicela: Indicaciones actuales de tratamiento y prevención
}

\author{
KATIA ABARCA V.
}

\section{Varicella: review on its treatment and prophylaxis}

Palabras claves: Varicela: tratamiento; profilaxis; aciclovir, vacuna. Key words: Varicella; treatment; prophylaxis; acyclovir, vaccine.

\section{Tratamiento}

\section{Medidas generales}

Uso de antipiréticos: se recomienda el uso preferencial de acetaminofeno (paracetamol). Está contraindicado el uso de ácido acetilsalicílico por el riesgo de desencadenar un síndrome de Reye. Algunos estudios han mostrado cierta asociación del uso de anti-inflamatorios no esteroidales en varicela con enfermedad invasora causada por Streptococcus pyogenes; mientras no existan mayores antecedentes se recomienda evitarlos.

Higiene y prurito: parte de la terapia está dirigida a aliviar el prurito y mantener la higiene de piel para prevenir la sobreinfección bacteriana. En este sentido, están desaconsejados las cremas y polvos que cubran las lesiones. El baño, de ducha en la medida de lo posible, debe ser fomentado cuidando no romper las lesiones y secando con toalla limpia sin frotar. El baño calma además el prurito; pueden usarse medicamentos antihistamínicos según el caso. Debe evitarse el rascado de lesiones porque favorece la sobreinfección, mantener las uñas cortas y limpias.

\section{Terapia antiviral específica}

Aciclovir es el antiviral de uso más extendido en varicela. Como, análogo de nucléosido (similar a la guanosina), es incorporado por la ADN polimerasa a la cadena de ADN en síntesis durante la replicación del genoma viral, con lo que ocurre una detención de la replicación. Es activo contra la mayoría de los virus de la familia
Herpesviridae, principalmente los virus herpes simplex tipos 1 y 2 y el virus varicela-zoster. Es administrado como una prodroga y debe fosforilarse tres veces para convertirse en un producto activo; la primera fosforilación la efectúa la timidina kinasa viral, posteriormente es doblemente fosforilado por kinasas propias del hospedero.

Aciclovir puede usarse por vía oral, endovenosa, tópica y ocular. Suele ser bien tolerado, con una baja frecuencia de efectos colaterales. Entre estos se han descrito molestias gastrointestinales, cefalea, exantema, flebitis por la administración endovenosa, e insuficiencia renal reversible descrita en pacientes deshidratados que reciben infusión intravenosa rápida del fármaco. Siempre debe infundirse aciclovir en al menos 1 hora.

Existen compuestos derivados de aciclovir: valaciclovir y famciclovir, cuyo espectro y mecanismo de acción son similares al fármaco original, pero con mejor biodisponibilidad, lo que permite el uso en menores dosis y mayor espaciamiento.

Indicaciones. Aciclovir está indicado en todos los sujetos con mayor riesgo de desarrollar varicela moderada a severa; estos grupos comprenden:

- Pacientes inmunocomprometidos. Deben ser tratados con aciclovir por vía parenteral, lo más precozmente posible, siendo máxima su eficacia si el tratamiento comienza antes de 24 a 48 horas de aparecer el exantema. Sin em- 
bargo, dado que en los inmunocomprometidos de la vertiente celular del sistema inmune la replicación viral es más prolongada, se recomienda iniciar aciclovir cualquier sea el grado de avance de la enfermedad. La dosis recomendada es: $10 \mathrm{mg} / \mathrm{kg}$ dosis cada 8 horas (30 $\mathrm{mg} / \mathrm{kg} /$ día) o $500 \mathrm{mg} / \mathrm{m}^{2}$ de superficie corporal cada 8 horas $\left(1.500 \mathrm{mg} / \mathrm{m}^{2}\right.$ día), durante 7 a 10 días por vía intravenosa. En niños es posible cambiar a aciclovir oral después de dos días de evolución sin aparición de nuevas lesiones.

- Otros grupos de riesgo. Adolescentes y adultos; personas con enfermedades crónicas cutáneas o pulmonares; terapia prolongada con salicilatos; terapia corticoesteroidal breve, intermitente o en aerosol (los pacientes con terapia corticoesteroidal prolongada deben ser considerados inmunocomprometidos y tratados como tales); lactantes bajo un año de edad, hijos de madres seronegativas; contactos en el hogar (algunos expertos recomiendan tratamiento de los casos secundarios en un hogar, en quienes el cuadro suele ser más severo). Para una mayor eficacia el inicio de la terapia debe ser lo más precoz posible, idealmente dentro de las primeras 24 horas de exantema y como máximo hasta las 72 horas. En estos pacientes se usa aciclovir por vía oral, la dosis en niños es: $20 \mathrm{mg} / \mathrm{kg} /$ dosis cada 6 horas $(80 \mathrm{mg} / \mathrm{kg} /$ día $)$ durante 5 días con un máximo de 3,2 g diarios. En adultos la dosis es: $800 \mathrm{mg}$ cada 4 horas por 5 veces al día (4 $\mathrm{g}$ diarios) durante 5 a 7 días. Como alternativa en adultos se puede usar valaciclovir: $1 \mathrm{~g}$ cada 8 horas durante 5 días.

- Mujeres embarazadas. No existe acuerdo respecto a la terapia rutinaria de la varicela en mujeres gestantes, algunos expertos no recomiendan el uso de aciclovir dada la falta de información respecto a seguridad en el feto, otros recomiendan su uso rutinario, vía oral, especialmente en el segundo y tercer trimestre de gestación. Su uso está destinado a prevenir las complicaciones severas de la varicela cuyo riesgo está aumentado por dos factores: ser adulto y además estar embarazada. No se ha comprobado que el uso de aciclovir prevenga la transmisión de la infección al feto. Aciclovir es considerado un medicamento en categoría $\mathrm{C}$ por la FDA (v gr.: no se pueden descartar riesgos, pero el potencial beneficio puede justificar los posibles riesgos). Estudios en animales no han mostrado efectos teratogénicos, pero no existen estudios controlados en mujeres embaraza- das que hayan establecido su seguridad. En caso de aparecer diseminación visceral de la varicela en la mujer embarazada (pulmonar u otra), está indicada la terapia endovenosa.

\section{- Tratamiento de varicela grave o complica- ciones derivadas del virus}

La varicela grave, diseminada, hemorrágica y la neumonía varicelatosa, a cualquier edad, deben ser tratadas con aciclovir por vía endovenosa, con similares dosis que las antes mencionadas.

Niños inmunocompetentes. La terapia con aciclovir no está indicada rutinariamente en niños inmunocompetentes, pues los beneficios obtenidos son marginales.

\section{Tratamiento del herpes zoster}

La eficacia de la terapia antiviral en reducir la neuralgia post herpética está especialmente demostrada en sujetos mayores de 50 años; en niños en cambio, no existen recomendaciones claras, pues en ellos la neuralgia es muchísimo menos severa que en adultos. Existen distintos esquemas de terapia antiviral para el herpes zoster:

- Pacientes inmunocompetentes. Valaciclovir 1 g 3 veces al día durante 7 días. Reduce la neuralgia post herpética más rápidamente que aciclovir. Famciclovir 500 mg 3 veces al día durante 7 días (ajustar dosis en insuficiencia renal), con similar eficacia que aciclovir. Aciclovir $800 \mathrm{mg} 5$ veces al día durante 7 a 10 días. En personas sobre 50 años de edad y, en especial si existe alto número de lesiones, se recomienda asociar al tratamiento antiviral prednisona. Otros esquemas asocian antidepresivos, analgésicos locales o infiltraciones regionales, etc.

- Pacientes inmunocomprometidos. Herpes zoster no grave: aciclovir $800 \mathrm{mg} 5$ veces al día durante 7 días. En caso de progresión, cambio a terapia endovenosa. Valaciclovir y famciclovir no están aprobados para esta indicación.

- Herpes zoster grave (más de un dermatoma, compromiso del nervio trigémino, herpes zoster diseminado): aciclovir $10 \mathrm{mg} / \mathrm{kg}$ cada 8 horas endovenoso durante 7 a 14 días. Deben emplearse dosis menores en pacientes ancianos y en presencia de daño renal o nefrotoxicidad. En los raros casos de resistencia a aciclovir (descrito en algunos pacientes con SIDA), está indicado el uso de foscarnet. 


\section{Prevención universal de varicela (profilaxis pre-exposición)}

Inmunización activa. La vacuna anti-varicela contiene virus vivo atenuado y ha sido producida a partir de la cepa Oka recuperada de un paciente que llevaba ese nombre. Se licenció en Japón en 1984 y en E.U.A. en 1995. La inmunogenicidad de esta vacuna es elevada, principalmente en niños entre 1 y 12 años, quienes presentan seroconversión en más de $95 \%$ luego de una dosis. Los jóvenes sobre 12 años y los adultos presentan tasas menores de seroconversión, por lo que requieren de dos dosis, espaciadas por 4 semanas entre sí. La eficacia global de la vacuna es de aproximadamente 85 a $90 \%$ y contra enfermedad moderada a grave, de 95 a $100 \%$. Es una vacuna bien tolerada, con baja frecuencia de efectos adversos. Ocasionalmente puede producir rash; en forma muy esporádica se ha descrito transmisión del virus vacuna, pero los casos así adquiridos han sido muy atenuados. Alrededor de 10 a $15 \%$ de los niños vacunados contra varicela pueden presentar la enfermedad tras una exposición natural; sin embargo, esta enfermedad suele ser atenuada. Durante los últimos años se ha visto que la varicela en niños vacunados ocurre con mayor frecuencia si la inmunización artificial se efectuó antes de los 14 meses de vida, situación que se acrecienta con el transcurso de los años. Las fallas son mucho menos frecuentes en individuos que reciben dos dosis. Sin embargo, aún no existe una recomendación formal de administrar una segunda dosis en niños pequeños, criterio que podría modificarse en caso de acumularse mayor evidencia.

Contraindicaciones. Por ser una vacuna que contiene un virus vivo atenuado, está contraindicada en los sujetos inmunocomprometidos de la vertiente celular y en la mujer embarazada. Por el contrario, se puede administrar en sujetos con deficiencias de la inmunidad humoral, en infección por VIH asintomática y en niños con leucemia linfática aguda (siempre y cuando estén en remisión de su enfermedad de base durante al menos un año y que tengan un recuento de linfocitos $>700 / \mathrm{mm}^{3}$ y plaquetas $>100.000 / \mathrm{mm}^{3}$ ). Se recomienda no administrar salicilatos durante las 6 semanas siguientes a la vacunación, por el riesgo teórico de desarrollar un síndrome de Reye. Se recomienda postponer la vacunación en sujetos que están cursando con una enfermedad aguda febril, y en personas que han recibido inmunoglobulinas (lapsos recomendados similares a los indicados para vacuna anti sarampión, que dependen del preparado y de la vía de administra- ción) o dosis altas de corticosteroides por más de 14 días (lapso recomendado desde la suspensión: 1 mes).

\section{Prevención de varicela en contactos (profilaxis post-exposición)}

\section{- Inmunoglobulina hiperinmune anti-varicela} zoster $(I G V Z)$. Este producto está indicado en individuos con alto riesgo de desarrollar una varicela grave (inmunocomprometidos, mujeres embarazadas, recién nacido cuya madre presenta varicela entre 5 días antes y 2 días después del parto, prematuros hospitalizados $\geq 28$ semanas hijos de madre sin historia de varicela, prematuros hospitalizados $<28$ semanas o $1 \mathrm{~kg}$ de peso, independiente de la historia materna), y que hayan tenido una exposición significativa con una persona que está cursando varicela o en su período preeruptivo (hasta 3 días antes del exantema). Se considera exposición significativa dormir en la misma casa, mantener un contacto cercano mayor de 1 hora en espacios cerrados o compartir habitación en hospital. La dosis de IGVZ es 1 ampolla de $1,25 \mathrm{~mL}$ (125 U) cada $10 \mathrm{~kg}$ de peso, por vía intramuscular. La dosis máxima es 625 U ó 5 ampollas, la dosis mínima es de 125 U ó 1 ampolla. Se debe administrar con la mayor precocidad posible, dentro de los 4 días (96 horas) de producido el contacto. La duración de la protección que otorga la IGVZ se estima en alrededor de 3 semanas.

Los pacientes que reciben regularmente (cada mes) dosis altas de inmunoglobulina endovenosa no requieren de la administración de IGVZ, si han recibido la inmunoglobulina endovenosa dentro de los 3 semanas previas.

En Chile, la IGVZ se encuentra disponible en el Stock Crítico Crítico de Medicamentos en la Farmacia del Hospital de Urgencia Asistencia Pública ex Posta Central. Fono: 56-2-4633761.

-Vacuna. La vacuna anti varicela está recomendada por la Academia Americana de Pediatría en el control de brotes, pues ha demostrado ser efectiva. Por falta de mayor información, aún no se ha incluido una recomendación explícita en otras situaciones de contacto. Diversos estudios en uso post-exposición en niños han mostrado que si la vacuna es administrada a individuos susceptibles dentro de los primeros 3 días y probablemente dentro de los primeros 5 días del contacto con el caso índice, puede prevenir o atenuar la enfermedad. Estos estudios han reportado una efi- 
cacia de alrededor de $67 \%$ a los 3 días del contacto y de $50 \%$ a los 5 días. Aún no existen suficientes estudios controlados respecto a este punto en adultos. No hay evidencia que la vacunación durante el período de incubación aumente el riesgo de eventos adversos.

- Aciclovir profiláctico. El uso de aciclovir durante la segunda semana después del contacto en niños sanos, ha mostrado atenuación o prevención de la varicela, por lo que esta alternativa podría considerarse en ciertos casos. Esta información proviene de sólo dos estudios con un reducido número de sujetos, por tanto, el uso de aciclovir preventivo no es una recomendación oficial. La dosis empleada es la misma empleada con fines terapéuticos, por vía oral, durante 5 días. Algunos sujetos que con esta medida no presentan varicela clínica continúan siendo susceptibles (profilaxis de infección exitosa), mientras que otros seroconvierten (infección silenciosa).

\section{Bibliografía}

1.- Whitley R J. Varicella-Zoster Virus. In: Mandell G L, Bennett J E, Dolin R, eds. Mandell, Douglas and Bennett's Principles and Practice of Infectious Diseases. Fifth edition, 2000; New York: Churchill Livingstone, pp: 1580-5.

2.- Recommendations of the Advisory Committee on Immunization Practices (ACIP). Prevention of varicella. Morbid Mortal Wkly Rep MMWR 1996; 45 (RR-12).

3.- American Academy of Pediatrics. Varicella-Zoster Infections. In: Peter G, ed. 2004 Red Book: Report of the Committee on Infectious Diseases. 24th edition, Elk GroveVillage, IL: American Academy of Pediatrics 2004; 510-20.

4.- Gershon A A, Takahashi M, Seward J. Varicella vaccine. In: Plotkin SA, Orenstein WA (eds) Vaccines. $4^{\text {th }}$ edition 2004. Saunders, Philadelphia 783-823.

5.- Watson B, Seward J, Yang A, et al. Postexposure effectiveness of varicella vaccine. Pediatrics 2000; 105: 84-88.

6.- Vacuna varicela en Chile 2000. Comité Consultivo de Inmunizaciones, Sociedad Chilena de Infectología. Rev Chil Infect 2001; 18: 225-9.

Correspondencia a:

Katia Abarca Villaseca

katia@med.puc.cl 